\title{
VIABILIDADE ECONÔMICA DE TECNOLOGIAS DE MANEJO DA IRRIGAÇÃO NA PRODUÇÃO DO FEIJÃO-CAUPI, NA REGIÃO DOS COCAIS-MA
}

Doi:http://dx.doi.org/10.1590/1809-4430-Eng.Agric.v35n3p 406-418/2015

\section{WADY L. CASTRO JÚNIOR ${ }^{1}$, RUBENS A. DE OLIVEIRA ${ }^{2}$, SUELY DE F. R. SILVEIRA ${ }^{3}$, ADERSON S. DE ANDRADE JÚNIOR ${ }^{4}$}

\begin{abstract}
RESUMO: O feijão-caupi é uma cultura de grande relevância socioeconômica nas regiões Norte e Nordeste do Brasil. No entanto, apresenta baixa produtividade. A irrigação é uma técnica que possibilita aumentos na produtividade e na rentabilidade dos cultivos, principalmente quando bem manejada. Para tanto, existem diversas tecnologias de manejo. Assim, objetivando avaliar economicamente diferentes tecnologias de manejo da irrigação na produção do feijão-caupi (Vigna unguiculata (L.) Walp.), em duas épocas de cultivo (primavera e outono), na região dos cocais, no Estado do Maranhão, conduziu-se um experimento no Campo Experimental do Instituto Federal do Maranhão, em Codó-MA, no delineamento em blocos casualizados, com sete tratamentos e quatro repetições. Deste modo, foi realizada uma análise econômica sob a ótica da teoria de investimentos, sem considerar a presença dos riscos na atividade. Verificou-se que o investimento na prod ução do feijão-caupi irrigado por aspersão convencional, nas condições edafoclimáticas da região dos cocais maranhenses, mostrou-se viável, independentemente da época de cultivo e/ou da tecnologia de manejo adotada. Entre as épocas de cultivo, observou-se que o plantio conduzido na época da primavera foi mais rentável para todos os tratamentos.
\end{abstract}

PALAVRAS-CHAVE: Vigna unguiculata (L.) Walp., rentabilidade, custo de prod ução.

\section{ECONOMIC FEASIBILITY OF IRRIGATION MANAGEMENT TECHNOLOGIES FOR COWPEA PRODUCTION IN THE COCAIS REGION (MARANHÃO STATE, BRAZIL)}

\begin{abstract}
Despite the low yield, cowpea is a crop of great socio-economic interest in Northern and Northeastern Brazil. Irrigation allows improvement in crop yield and profitability, especially when properly handled, for which, several management technologies are available. Thus, this study aimed to evaluate, economically, different irrigation management technologies to cultivate cowpea [Vigna unguiculata (L.) Walp.] in two growing seasons (spring and fall) in the Cocais region, Maranhão State, Brazil. We carried out a trial at an experimental area of the Institute of Maranhão, in Codó County. The experiment was performed in a randomized block design with seven treatments and four replications. Thereby, it was performed an economic analysis from the perspective of sound investment opportunity, without considering risks associated with this activity. We found that, regardless growing season and/ or management technology, it was feasible to grow cowpea under conventional sprinkling irrigation at the conditions of the Cocais region. Furthermore, it was observed that spring cropping was more profitable for all treatments.
\end{abstract}

KEYWORDS: Vigna unguiculata (L.) Walp., profitability, production costs.

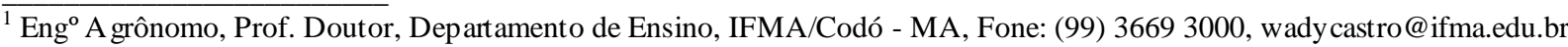

${ }^{2}$ Eng $^{\circ}$ A grícola, Prof. Doutor, Departamento de engenharia Agrícola, UFV/Viçosa - MG, rubens@ @ ufv.br

${ }^{3}$ Economista, Prof ${ }^{a}$ Doutora, Departamento de Administração e Contabilidade/IPPDS, UFV/Viçosa - MG, sramos@ ufv.br

${ }^{4}$ Eng $^{\circ}$ A grônomo, Doutor, Pesquisador, Centro de Pesquisa Agropecuária do Meio-Norte, Embrapa Meio-Norte/Teresina - PI, aderson.andrade@embrapa.br 


\section{INTRODUÇÃO}

O cultivo do feijão-caupi (Vigna unguiculata (L.) Walp), no Brasil, embora mais concentrado nas regiões Norte e Nordeste, tem-se expandido recentemente em áreas do Centro Oeste e Sudeste. No estado do Maranhão, especificamente, esta cultura desempenha um papel de grande relevância socioeconômica, sendo considerada uma das mais importantes culturas de subsistência.

Embora a produtividade nacional seja baixa $\left(426 \mathrm{~kg} \mathrm{ha}^{-1}\right)$, a produção do feijão-caupi tem, cada vez mais, deixado os padrões tradicionais de cultivo com a aquisição de maior expressão econômica. Seu cultivo é feito tanto por pequenos como por médios e grandes produtores, que utilizam alta tecnologia (FREIRE FILHO et al., 2005). Alguns produtores de estados consagrados na produção agrícola brasileira, como o Mato Grosso, têm substituído parte da área destinada à produção de soja para cultivo do feijão-caupi. Isto é devido ao bom preço do produto, no Brasil e exterior, aliado ao baixo custo de produção (OLIVEIRA, 2010).

A irrigação é uma tecnologia que potencializa aumentos de produtividade na agricultura, sendo importante estabelecer um programa de manejo da irrigação. Para tanto, existem diversos métodos que podem ser empregados.

Entretanto, as plantas exigem elevados volumes de água e há, no mundo, uma crescente escassez qualitativa deste recurso (BERNARDO, 2008). Desta maneira, a adoção do manejo racional da irrigação, além de atuar como medida capaz de aumentar a economia deste recurso hídrico, mitigando o impacto ambiental causado pela irrigação, tem-se o viés econômico dos agricultores, incentivando-os a melhorar a eficiência na alocação dos recursos, permitindo-lhes aumentar sua produtividade e renda, de tal forma que possam competir no mercado. Com a adoção do manejo racional da irrigação, podem-se obter melhorias econômicas na atividade agrícola.

Essa necessidade de melhorias econômicas, associada à competição pelo uso da água e dos impactos ambientais decorrentes do uso da irrigação, são fatores relacionados por FRIZZONE (2004), que deverão motivar mudança de paradigma da irrigação, enfocando-se mais a eficiência econômica do que apenas suprir a demanda hídrica das plantas.

O manejo tradicional da irrigação geralmente tem sido empregado com o objetivo de maximizar a produtividade, esquecendo-se de observar os aspectos econômicos. Entrementes, de acordo com FIGUEIREDO et al. (2008), irrigar visando a maximizar o lucro é um problema substancialmente mais complexo e desafiador que irrigar buscando o máximo rendimento físico. Isto é, uma irrigação ótima, sob o foco econômico, implica a aplicação de menores lâminas em relação à irrigação plena, mesmo que ocorra alguma consequente redução de produtividade, mas com alguma vantagem econômica significativa.

Em cultivos irrigados, pode haver situações nas quais a maior produtividade física não coincida com a maior rentabilidade, pois irrigar gera custos, e os incrementos no rendimento por área podem não compensar economicamente a aplicação de maiores lâminas de irrigação.

Assim, objetivou-se com este estudo avaliar economicamente diferentes tecnologias de manejo da irrigação na produção do feijão-caupi (Vigna unguiculata (L.) Walp.), em duas épocas de cultivo, na região dos Cocais, no Estado do Maranhão. O fato de estudar a viabilidade econômica em duas épocas $($ safra $=$ outono, e entressafra $=$ primavera) deve-se ao interesse de analisar o comportamento das tecnologias de manejo em diferentes condições climáticas, assim como a análise econômica sob condições de preços diferenciados do produto.

\section{MATERIAL E MÉTODOS}

O estudo foi conduzido com a cultura do feijão-caupi (Vigna unguiculata (L). Walp.), no Campo Experimental do Instituto Federal de Educação, Ciência e Tecnologia do Maranhão, Campus Codó, localizado no município de Codó-MA, com coordenadas geográficas de $4^{\circ} 26^{\prime} 51$ '" $\mathrm{S}, 43^{\circ} 52^{\prime}$ '57' $\mathrm{O}$ e com altitude de $48 \mathrm{~m}$. 
A cultura utilizada foi o feijão-caupi (Vigna unguiculata (L.) Walp.), cultivar BR 17 Gurgueia, pertencente à Classe Cores, Subclasse Sempre Verde. Seu porte é semienramador, ciclo de 65 a 80 dias e produtividade de grãos esperada de $2.000 \mathrm{~kg} \mathrm{ha}^{-1}$ (FREIRE FILHO et al., 2005).

O preparo do solo foi realizado com uma aração e uma gradagem. Foram efetuados dois cultivos, um na primavera e o outro no outono. $O$ espaçamento adotado foi de $0,60 \mathrm{~m}$ entre fileiras de plantas, com uma densidade de dez plantas por metro na linha de plantio. O sistema de irrigação utilizado foi a aspersão convencional.

O delineamento experimental foi o em blocos casualizados, com sete tratamentos e quatro repetições. Os tratamentos foram constituídos pelas lâminas recomendadas pelas diferentes tecnologias de manejo da irrigação, sendo $\mathrm{T}_{1}$ : Determinação da umidade do solo com forno de micro-ondas; $\mathrm{T}_{2}$ : Tanque Classe $\mathrm{A} ; \mathrm{T}_{3}$ : Irrigâmetro; $\mathrm{T}_{4}$ : Tensiômetro; $\mathrm{T}_{5}$ : Irrígrafo; $\mathrm{T}_{6}$ : Balanço hídrico com o software Ref-ET, e $\mathrm{T}_{7}$ : Balanço hídrico com o software Irriplus.

Ao final de cada cultivo, foram coletadas as plantas da área útil da parcela experimental $(3,84$ $\mathrm{m}^{2}$ ), nas quais foram determinados: número de vagens por planta, número de grãos por vagem e produtividade de grãos. Durante o ciclo da cultura, foram contabilizadas as lâminas de água recomendadas pelas diferentes tecnologias de manejo da irrigação, permitindo-se o cálculo da eficiência do uso da água.

Para o estudo da viabilidade econômica, levantou-se o custo de investimento em um sistema de irrigação por aspersão convencional semiportátil, capaz de irrigar uma área de 10 hectares. As características hidráulicas gerais do projeto de irrigação são: comprimento da linha lateral = $134 \mathrm{~m}$; comprimento da linha principal $=350 \mathrm{~m}$; comprimento da linha de recalque $=100 \mathrm{~m}$; comprimento da linha de sucção $=5 \mathrm{~m}$; vazão do sistema $=33,6 \mathrm{~L} \mathrm{~s}^{-1}$; altura manométrica $=57,29 \mathrm{~m} \mathrm{c}$.a.; potência da bomba $=40 \mathrm{cv}$; potência do motor elétrico $=45 \mathrm{cv}$. Assim, o valor estimado e considerado nesta pesquisa para o referido sistema ficou em $\mathrm{R} \$ 51.149,65$. Entretanto, não fizeram parte deste valor as obras civis, os custos inerentes à elaboração do projeto de irrigação, mão de obra da instalação elétrica e componentes elétricos como: transformador, linha de alta tensão, cabos elétricos e quadro de proteção e partida do motor. Desta maneira, o investimento por hectare foi igual a R\$ 5.114,97 (US\$ 2.527,41) ${ }^{1}$. Este valor está acima do estipulado por SOUZA (2001), citado por FRIZZONE \& ANDRADE JÚNIOR (2005), de US\$ 875,00 ha ${ }^{-1}$.

Nesta análise, considerou-se a realização de apenas um cultivo ao ano, feito na primavera ou outono, na mesma área, devido às implicações agronômicas, tal como doença de solo.

O custo total de produção decorre do somatório dos custos fixos e variáveis da produção do feijão-caupi irrigado, conforme a [eq. (1)].

$$
\mathrm{CT}=\mathrm{CF}+\mathrm{CV}
$$

em que,

$\mathrm{CT}$ - custo total de produção, $\mathrm{R} \$ \mathrm{ha}^{-1}$;

$\mathrm{CF}$ - custo fixo da produção, $\mathrm{R} \$ \mathrm{ha}^{-1}$,

$\mathrm{CV}$ - custo variável da produção, $\mathrm{R} \$ \mathrm{ha}^{-1}$.

Como este estudo tem o intuito de avaliar a produção de feijão-caupi irrigado sob a recomendação de variadas tecnologias de manejo da irrigação, o custo total de produção pode ser assim especificado (JOBIM et al., 2009):

$$
\mathrm{CT}=\mathrm{C}_{0}+\mathrm{C}_{\mathrm{i}}
$$

em que,

$\mathrm{CT}$ - custo total de produção, $\mathrm{R} \$ \mathrm{ha}^{-1}$;

\footnotetext{
${ }^{1}$ Cotação R\$ 2,026, em 24-03-2013.
} 

$\mathrm{C}_{0}$ - custo básico associado à produção, $\mathrm{R} \$ \mathrm{ha}^{-1}$,
$\mathrm{C}_{\mathrm{i}}$ custo referente à irrigação, $\mathrm{R} \$ \mathrm{ha}^{-1}$.

Para os cálculos referentes aos custos da produção do feijão-caupi $\left(\mathrm{C}_{0}\right)$, foram considerados gastos com mão de obra para o plantio, tratos culturais e colheita, preparo de solo, calagem, fertilizantes, agrotóxicos e sementes.

O custo de irrigação, por sua vez, foi obtido por:

$$
\mathrm{C}_{\mathrm{i}}=\mathrm{c}_{\mathrm{c}}+\mathrm{C}_{\mathrm{w}}
$$

em que,

$\mathrm{C}_{\mathrm{c}}$ - custo de capital referente ao investimento com o equipamento de irrigação, $\mathrm{R} \$ \mathrm{ha}^{-1}$;

$\mathrm{C}_{\mathrm{w}}$ - custo operacional da irrigação, $\mathrm{R} \$ \mathrm{ha}^{-1}$.

Como FRIZZONE \& ANDRADE JÚNIOR (2005), o custo de capital foi obtido pela utilização da [eq. (4)]. Observa-se, pela equação, que há consideração da depreciação e da remuneração do capital investido, que é referente ao valor que o produtor receberia se esses recursos estivessem aplicados em outra oportunidade. Assim, essa equação leva em consideração não somente a reposição do bem, como também busca contemplar o juro sobre o capital investido. Ou seja, o custo de capital $\mathrm{C}_{\mathrm{c}}$ representa o custo anual uniforme equivalente ao investimento efetuado com a aquisição do sistema de irrigação.

$$
C_{c}=\left(V_{i}-V_{r}\right)\left[\frac{j}{(1+j)^{n}-1}\right]+V_{i} \mathbf{j}
$$

em que,

$\mathrm{V}_{\mathrm{i}}$ - valor inicial do investimento, $\mathrm{R} \$ \mathrm{ha}^{-1}$;

$\mathrm{V}_{\mathrm{r}}$ - valor residual do investimento, $\mathrm{R} \$ \mathrm{ha}^{-1}$;

$\mathrm{n}$ - vida útil do equipamento, ano,

$\mathrm{j}$ - taxa de juros sobre o capital investido, decimal.

A depreciação é o custo necessário para substituir os bens de capital quando tornados inúteis pelo desgaste físico ou quando perdem o valor com o decorrer dos anos, em razão das inovações técnicas, e foi calculada pela seguinte equação:

$$
\mathrm{D}=\frac{\mathrm{V}_{\mathrm{i}}-\mathrm{V}_{\mathrm{r}}}{\mathbf{n}}
$$

Os custos incorridos na manutenção, conservação e reparo de equipamentos (CMCR) foram calculados de acordo com MARQUES (2005). Pela [eq. (6)], percebe-se que foi fixada uma percentagem sobre o valor de investimento, mormente nos referentes à irrigação, a ser diluído no horizonte temporal do projeto. Assim, este custo não variaria com a produção e, portanto, foi considerado como custo fixo de produção.

$$
\text { CMCR }=0,03 \times v_{\mathrm{i}}
$$

A mão de obra (MO) e consequentes encargos (férias, 13ํㅗ salário e INSS), neste estudo, também foram atribuídos aos custos fixos, pois na região em análise verifica-se que os irrigantes não trabalham somente como tal, mas executam outras atividades, como reparos nas benfeitorias, atividades de lavoura, manutenções diversas, entre outros. Além dis to, os funcionários normalmente recebem remuneração fixa. 
Como a outorga de água ainda não tem sido realizada na região em análise, considerou-se, para o cálculo do cus to operacional da irrigação $\left(\mathrm{C}_{\mathrm{w}}\right)$, o custo de bombeamento estimado pelo custo da energia elétrica consumida pelo sistema de irrigação por aspersão convencional, o qual pode ser estimado pela equação adaptada de FRANKE (1996), citado por FRIZZONE \& ANDRADE JÚNIOR (2005), como segue:

$$
\mathrm{CE}=\left(\mathrm{Eb} \times \mathrm{tc}_{\mathrm{c}}\right)+(\mathrm{Dp} \times \mathrm{td})+[\mathrm{Dp} \times \mathrm{td} \times \mathrm{y} \times(12-\mathrm{X})]
$$

em que,

$\mathrm{CE}$ - custo de energia elétrica durante o ciclo do feijão-caupi, $\mathrm{R} \$ \mathrm{ha}^{-1}$;

$\mathrm{Eb}$ - energia requerida pela unidade de bombeamento, $\mathrm{kWh} \mathrm{ha}^{-1}$;

tc - tarifa média mensal de consumo de energia elétrica, $\mathrm{R} \$ \mathrm{kWh}^{-1}$;

Dp - demanda de potência da unidade de bombeamento, $\mathrm{kWh} \mathrm{ha}^{-1}$;

td - tarifa média mensal da demanda de potência, $\mathrm{R} \$ \mathrm{kWh}^{-1}$;

$\mathrm{y}$ - coeficiente aplicado à demanda faturável $=0,1$ da maior demanda verificada por medição nos últimos 11 meses,

$\mathrm{X}$ - número de meses que o sistema opera pelo menos uma vez.

Entretanto, na região em estudo, as propriedades rurais são enquadradas na classe rural de consumo de energia elétrica sobre a qual incide apenas a tarifa de consumo B2 - Rural (ANEEL, 2011), que independe da potência elétrica instalada na propriedade. Sobre estes produtores, não incide a cobrança da tarifa de demanda, assim como não se aplicam as tarifas horossazonais. Portanto, o custo de energia elétrica passou a ser estimado por uma simplificação da [eq. (7)].

$$
\mathrm{CE}=\mathrm{Eb} \times \mathrm{tc}
$$

Sendo,

$$
\mathrm{Eb}=\left(\frac{10 \times \mathrm{W} \times \mathrm{Hm} \times \mathrm{V}_{\mathrm{a}}}{3,6 \times 10^{6} \times \eta}\right)
$$

Logo,

$$
\mathrm{CE}=\mathrm{C}_{\mathrm{w}}=\left(\frac{10 \times \mathrm{W} \times \mathrm{Hm} \times \mathrm{v}_{\mathrm{a}}}{3,6 \times 10^{6} \times \eta}\right) \times \mathrm{tc}
$$

em que,

W - lâmina bruta de irrigação necessária, recomendada pela respectiva tecnologia de manejo analisada, durante o ciclo do feijão-caupi, $\mathrm{mm} \mathrm{ha}^{-1}$;

$\mathrm{Hm}$ - altura manométrica total, m;

$\gamma_{\mathrm{a}}$ - peso específico da água, $\mathrm{N} \mathrm{m}^{-3}$,

$\eta$ - eficiência do conjunto motobomba, decimal.

Deste modo, o custo total de produção do feijão-caupi, com irrigação manejada por diferentes métodos, passa a ser expresso como:

$$
\mathrm{CT}=\mathrm{C}_{0}+\mathrm{C}_{\mathrm{c}}+\mathrm{CMCR}+\mathrm{Mo}+\mathrm{C}_{\mathrm{w}}
$$

Assumindo, como condição simplificadora, que a soma dos custos básicos associados à produção $\left(\mathrm{C}_{0}\right)$ e dos custos de capital referentes ao investimento no equipamento de irrigação $\left(\mathrm{C}_{\mathrm{c}}\right)$, além dos custos de manutenção, conservação e reparo de equipamentos (CMCR), e da mão de obra (MO) são constantes $\left(\mathrm{C}_{\mathrm{f}}\right)$, pode-se expressar a função de custo total de produção da maneira sugerida por FRIZZONE (2007). 


$$
\mathrm{CT}(\mathrm{w})=\mathrm{C}_{\mathrm{f}}+\mathrm{C}_{\mathrm{w}}
$$

Assim, analis ando-se a [eq. (10)], nota-se que o componente da lâmina bruta de irrigação (W) é o único que variaria entre as recomendações dos métodos de manejo para o mesmo sistema de irrigação. Portanto, para melhor expressão da função de custo total de produção, fez-se:

$$
\mathrm{C}_{\mathrm{Wa}}=\left(\frac{10 \times \mathrm{Hm} \times \mathrm{Y}_{\mathrm{a}}}{3,6 \times 10^{6} \times \eta}\right) \times \mathrm{tc}
$$

em que,

$\mathrm{C}_{\mathrm{wa}}$ - custo da lâmina de irrigação, $\mathrm{R} \$ \mathrm{ha}^{-1} \mathrm{~mm}^{-1}$.

Desta maneira, a função de custo total de produção pode ser expressa como:

$$
\mathrm{CT}(\mathrm{w})=\mathrm{C}_{\mathrm{f}}+\mathrm{C}_{\mathrm{Wa}} \times \mathrm{W}
$$

A viabilidade econômica da produção de feijão-caupi irrigado sob a recomendação das variadas tecnologias de manejo foi realizada por meio dos métodos que consideram a dimensão do tempo de valores monetários. Neste estudo, como foi analisada a estrutura de custos e receitas da produção do feijão-caupi irrigado sob os variados métodos de manejo para duas épocas do ano de 2010-2011, em caráter experimental, e a possível implantação do sistema de irrigação no cultivo dessa leguminosa, trata-se de uma análise ex ante, em que a utilização de preços constantes é considerada a mais adequada.

Todas as propostas de investimento apresentam fluxos de entrada e saída de recursos. A diferença entre esses fluxos chama-se fluxo líquido, sobre o qual se aplicam as técnicas de desconto para calcular a rentabilidade dos investimentos. Desta maneira, para fins desta pesquisa, adotam-se 15 anos como o horizonte temporal do projeto, que por sua vez está sendo tomado como a vida útil do equipamento de irrigação. Assim, após serem verificadas as entradas e saídas, construiu-se o fluxo de caixa com taxa de desconto de $6,75 \%$ ao ano - considerando-se o cultivo de um pequeno produtor rural - (BNB, 2011), sendo que os critérios de análise da viabilidade econômica estudados foram:

\section{a) Valor Presente Líquido (VPL)}

O valor presente líquido é definido como a diferença entre o valor presente dos benefícios e o valor presente dos custos. A característica essencial desse critério é que os benefícios e os custos são referenciados ao presente, isto é, os fluxos de caixa esperados durante a vida útil do projeto são descontados para o tempo zero, a uma taxa de juros que representa o mínimo retorno para o capital, ou seja, a Taxa Mínima de Atratividade - TMA - (FRIZZONE \& ANDRADE JÚNIOR, 2005). Assim, o critério de decisão consiste em aceitar o investimento se o VPL for maior que zero. O VPL pode ser calculado por meio da seguinte equação:

$$
\text { VPL }=\sum_{t=0}^{N} \frac{F_{t}}{(1+j)^{t}}
$$

em que,

VPL - valor presente líquido, em $\mathrm{R} \$ \mathrm{ha}^{-1}$;

j - taxas de desconto ou taxa mínima de atratividade (TMA), em decimal;

$\mathrm{N}$ - horizonte do projeto, em anos;

$\mathrm{t}$ - tempo (período) do projeto, em anos,

$F_{t}$ - fluxo de caixa líquido em cada ano, em $R \$ h^{-1}$. 
b) Taxa Interna de Retorno (TIR)

A taxa interna de retorno de um projeto é o valor da taxa de desconto que torna nulo o valor presente líquido. É nessa taxa que a soma dos benefícios se torna igual à soma dos custos, pois o valor presente líquido é a soma algébrica, no instante zero, dos benefícios e dos custos. Desta maneira:

$$
\sum_{t=0}^{N} \frac{F_{t}}{(1+\rho)^{t}}=0
$$

em que,

$\rho=$ taxa interna de retorno, em decimal.

Após o cálculo da TIR, ela deve ser comparada com a taxa de desconto. Sendo o projeto aceito, se apresentar TIR maior ou igual à taxa de desconto. A TIR, desta maneira, é a taxa que torna o valor dos lucros futuros equivalente aos gastos realizados com o projeto, caracterizando, desse modo, a taxa de remuneração do capital investido.

c) Razão Benefício/Custo

Considerando-se um fluxo de caixa, existem benefícios e custos. Obtendo-se a soma dos valores presentes de todos os benefícios, bem como de todos os custos, pode-se encontrar o valor presente líquido do fluxo de caixa.

A razão benefício/custo possibilita verificar se os benefícios atualizados são maiores que os desembolsos atualizados. No caso de a relação B/C ser superior a 1, pressupõe-se um VPL positivo, bem como a viabilidade econômica do investimento, dada a taxa de desconto considerada.

Esta razão pode ser calculada por meio da seguinte equação:

$$
B / C=\frac{\sum_{t=0}^{N} B /(1+j)^{t}}{\sum_{t=0}^{N} C /(1+j)^{t}}
$$

em que,

$\mathrm{B} / \mathrm{C}$ - razão benefício/custo;

$\mathrm{B}$ - receitas, em $\mathrm{R} \$ \mathrm{ha}^{-1}$,

$\mathrm{C}$ - despesas, em $\mathrm{R} \$ \mathrm{ha}^{-1}$.

\section{RESULTADOS E DISCUSSÃO}

Durante o cultivo do feijão-caupi realizado na primavera, houve a precipitação total de $74,4 \mathrm{~mm}$, enquanto o cultivado no outono recebeu $142,4 \mathrm{~mm}$ de chuva. Isto implicou maiores lâminas totais de irrigação na primavera quando comparado com o cultivo do outono, o que interferiu nos custos de produção associados à irrigação.

$\mathrm{Na}$ Tabela 1, são apresentados os componentes do custo total da produção do feijão-caupi irrigado sob as diferentes tecnologias de manejo, para duas épocas de cultivo. Os custos básicos com a produção do feijão-caupi $\left(\mathrm{C}_{\mathrm{o}}\right)$ foram constituídos pelos gastos com aquisição de fertilizantes, corretivos, agrotóxicos, sementes, preparo do solo (uma aração e uma gradagem), mão de obra para o plantio, aplicação de agro tóxicos e colheita manual (incluindo o ensacamento).

O valor encontrado para Co de $\mathrm{R} \$ 957,00 \mathrm{ha}^{-1}$ é superior ao relatado por CARDOSO et al. (1995) de US\$322,91 ha ${ }^{-1}$. MOUSINHO (2005), avaliando a viabilidade econômica da irrigação do feijão-caupi no Estado do Piauí, também utilizou este valor. No entanto, para a taxa vigente à época 
(US\$ 1,00 = R\$ 2,60), foi o equivalente a R\$ 839,57. ANDRADE JÚNIOR et al. (2002) afirmou que o custo médio de produção do feijão-caupi, excetuando-se o custo da água de irrigação, foi US\$ $882,35 \mathrm{ha}^{-1}$, para condições de solo arenoso e de baixa fertilidade natural. Este valor, como verificado, está acima do encontrado nesta pesquisa. Estas diferenças podem ser atribuídas às constantes variações nos preços dos insumos agrícolas e serviços.

TABELA 1. Custos por hectare para cultivo do feijão-caupi irrigado por aspersão convencional, no biênio de 2010-2011, em Codó-MA. Production costs per hectare of cowpea under sprinkling irrigation for the 2010-2011 biennium in Codó-MA, B razil.

\begin{tabular}{ccccccccc}
\hline & & $\mathrm{Co}^{1}$ & $\mathrm{Cc}^{2}$ & $\mathrm{Cw}^{3}$ & $\mathrm{Ci}^{4}$ & $\mathrm{CMCR}^{3}$ & $\mathrm{MO}^{6}$ & $\mathrm{CT}^{\prime}$ \\
\cline { 2 - 7 } Trat. & Época & \multicolumn{7}{c}{$\left(\mathrm{R} \$ \mathrm{ha}^{-1}\right)$} \\
\hline $\mathrm{T} 1$ & $\mathrm{P}$ & 957,00 & 552,76 & 138,77 & 691,53 & 153,45 & 232,50 & $2.034,47$ \\
& $\mathrm{O}$ & 957,00 & 552,76 & 72,68 & 625,44 & 153,45 & 232,50 & $1.968,38$ \\
$\mathrm{~T} 2$ & $\mathrm{P}$ & 957,00 & 552,76 & 106,39 & 659,15 & 153,45 & 232,50 & $2.002,10$ \\
& $\mathrm{O}$ & 957,00 & 552,76 & 85,15 & 637,92 & 153,45 & 232,50 & $1.980,86$ \\
$\mathrm{~T} 3$ & $\mathrm{P}$ & 957,00 & 552,76 & 108,59 & 661,35 & 153,45 & 232,50 & $2.004,29$ \\
& $\mathrm{O}$ & 957,00 & 552,76 & 65,80 & 618,56 & 153,45 & 232,50 & $1.961,50$ \\
$\mathrm{~T} 4$ & $\mathrm{P}$ & 957,00 & 552,76 & 106,13 & 658,89 & 153,45 & 232,50 & $2.001,84$ \\
& $\mathrm{O}$ & 957,00 & 552,76 & 67,64 & 620,40 & 153,45 & 232,50 & $1.963,35$ \\
$\mathrm{~T} 5$ & $\mathrm{P}$ & 957,00 & 552,76 & 117,73 & 670,49 & 153,45 & 232,50 & $2.013,43$ \\
& $\mathrm{O}$ & 957,00 & 552,76 & 64,23 & 616,99 & 153,45 & 232,50 & $1.959,94$ \\
$\mathrm{~T} 6$ & $\mathrm{P}$ & 957,00 & 552,76 & 122,89 & 675,65 & 153,45 & 232,50 & $2.018,60$ \\
& $\mathrm{O}$ & 957,00 & 552,76 & 84,02 & 636,78 & 153,45 & 232,50 & $1.979,73$ \\
$\mathrm{~T} 7$ & $\mathrm{P}$ & 957,00 & 552,76 & 93,67 & 646,43 & 153,45 & 232,50 & $1.989,38$ \\
& $\mathrm{O}$ & 957,00 & 552,76 & 72,20 & 624,96 & 153,45 & 232,50 & $1.967,91$ \\
\hline
\end{tabular}

1:Co - custos básicos associados à produção; $2: \mathrm{Cc}$ - custo de capital referente ao investimento no equipamento de irrigação; $3:$ Cw custo operacional da irrigação; 4:Ci - custo referente à irrigação; 5:CMCR - custo referente à manutenção, conserv ação e reparos no equipamento de irrigação; 6:MO - custo com mão de obra; 7:CT - custo total de produção; T1 - determinação da umidade do solo com o uso do forno de micro-ondas; T2 - tanque Classe A; T3 - Irrigâmetro; T4 - tensiometria; T5 - Irrígrafo; T6 - balanço hídrico com software Ref-ET; T7 - Balanço hídrico com software Irriplus; P - primavera; O - outono.

$\mathrm{O}$ custo de capital referente ao investimento no equipamento de irrigação $(\mathrm{Cc})$ foi de $\mathrm{R} \$$ $552,76 \mathrm{ha}^{-1}$ (Tabela 1). Este foi obtido partindo-se de um valor inicial de investimento igual a $\mathrm{R} \$$ $5.114,97 \mathrm{ha}^{-1}$, com uma taxa de desconto de $6,75 \%$ ao ano e uma vida útil do equipamento de 15 anos. Valor mais baixo foi utilizado por ANDRADE JÚNIOR et al. (2002), que em sua análise usaram um custo de aquisição de um sistema de aspersão convencional de US\$1.600,00 ha-1 (US\$ $1,00=\mathrm{R} \$ 2,60$ ). Este aumento no custo obtido nesta pesquisa foi devido a alterações nos preços dos componentes. Além disto, há que se relatar que, normalmente, à medida que se aumenta a área do projeto de irrigação, há uma tendência à diminuição do custo por hectare, devido à diluição dos custos fixos.

Os custos referentes à irrigação $(\mathrm{Ci})$ variaram conforme a tecnologia de manejo da irrigação, sendo que, para o cultivo realizado na primavera, o manejo conduzido com a determinação da umidade do solo com o forno de micro-ondas (T1) obteve o maior valor ( $\mathrm{R} \$ 691,53 \mathrm{ha}^{-1}$ ), e o menor custo com o manejo utilizando o software Irriplus (T7) - R \$646,43 $\mathrm{ha}^{-1}$. No outono, o custo de irrigação variou de $\mathrm{R} \$ 616,99 \mathrm{ha}^{-1}$ com o Irrígrafo (T5) a $\mathrm{R} \$ 637,92 \mathrm{ha}^{-1}$ com o tanque Classe A (T2). TURCO et al. (2009) também encontraram o manejo realizado com balanço hídrico climatoló gico utilizando o tanque Classe A com o maior consumo e custo de bombeamento, quando analisaram o consumo e o custo de energia elétrica na cultura do feijoeiro comum irrigado por pivô central, em relação ao manejo efetuado com o tensiômetro em sistema de plantio convencional. Contudo, não perceberam diferenças estatísticas quanto à produtividade de grãos.

O custo operacional da irrigação $(\mathrm{Cw})$ foi calculado utilizando-se do preço da tarifa da energia elétrica igual a $\mathrm{R} \$ 0,24799 \mathrm{kWh}^{-1}$, conforme Resolução Homologatória 1.194, especificada em ANEEL (2011). 
Para o cômputo do valor da mão de obra (MO), consideraram-se apenas três meses de atividade ao ano, haja vista ser este o tempo necessário para o cultivo do feijão-caupi. $\mathrm{O}$ custo obtido para este item foi igual a $\mathrm{R} \$ 232,50 \mathrm{ha}^{-1}$.

Por fim, o custo total (CT) de produção do feijão-caupi, a exemplo do que ocorreu com o custo de irrigação, obteve valores maiores para o cultivo da primavera e menores para o outono; com as tecnologias de manejo da irrigação: T1 (R\$ 2.034,47 ha $\left.{ }^{-1}\right)$ e T7 (R\$ 1.989,38 ha $\left.{ }^{-1}\right)$, respectivamente, com o maior e menor CT, na primavera, e T2 (R\$ 1.980,86 ha $\left.{ }^{-1}\right)$ e T5 (R\$ $\left.1.959,94 \mathrm{ha}^{-1}\right)$, respectivamente, com o maior e menor CT, no outono. Observa-se que a amplitude entre os custos totais no outono foi menor em relação ao cultivo efetuado na primavera (Tabela 1), o que se deve às diferenças nas recomendações de lâminas de irrigação entre as épocas.

Estes valores estão um pouco acima dos obtidos por MOUSINHO (2005), que simulou cultivos irrigados do feijão-caupi, em diferentes cidades do Piauí, e encontrou o custo de produção igual a R \$ 1.629,32 ha ha $^{-1}$ US 626,66, com taxa de câmbio de R 2,60 US\$ ${ }^{-1}$ ) para São Raimundo Nonato-PI.

ANDRADE JÚNIOR (2000), com o feijão-caupi irrigado nas condições edafoclimáticas de Parnaíba-PI, em diferentes combinações de épocas de semeadura, nível de manejo e nível de risco de $20 \%$, encontrou, em média, o custo total de produção igual a US\$759,01 ha ${ }^{-1}$ (R $\$ 1,85$ US $\$^{-1}$ ). RAMOS (2011), avaliando estratégias de irrigação do feijão-caupi para produção de grãos verdes em Teresina-PI, obteve um custo de produção em regime irrigado por aspersão convencional, igual a US\$ 882,00 (R\$ $\left.1,70 \mathrm{US}^{-1}\right)$.

No cultivo do feijão-caupi, independentemente da tecnologia de manejo da irrigação, o custo da energia elétrica variou de $4,7 \%$ a $6,8 \%$ e de $3,3 \%$ a $4,3 \%$ do custo total de produção, respectivamente, para as épocas de cultivo na primavera e outono. Estes percentuais aproximaramse bastante da faixa de variação de 4,6 \% a 6,2 \% obtida por ANDRADE JÚNIOR (2000), principalmente no que se refere à primavera.

Ressaltando-se as eqs. (11) e (12), que retratam a função de custo total de produção, observase que o cus to fixo $\left(\mathrm{C}_{\mathrm{f}}\right)$ é obtido pela soma dos custos básicos associados à produção $\left(\mathrm{C}_{\mathrm{o}}\right)$, custos de capital referente ao investimento no equipamento de irrigação $\left(\mathrm{C}_{\mathrm{c}}\right)$, custo de manutenção, conservação e reparo dos equipamentos (CMCR), e custos com mão de obra (MO). Assim, o custo fixo foi $\mathrm{R} \$ 1.895,71 \mathrm{ha}^{-1}$.

Com uso da [eq. (13)], obtém-se o custo da lâmina de irrigação $\left(\mathrm{C}_{\mathrm{wa}}\right)$, que foi de $\mathrm{R} \$ 0,5954123 \mathrm{ha}^{-1} \mathrm{~mm}^{-1}$. Desta maneira, utilizando-se da Equação 14, observou-se que o custo total por hectare da produção do feijão-caupi irrigado por aspersão convencional, nas condições edafoclimáticas da região dos cocais maranhenses, obtidos neste estudo, pode ser expresso por:

$$
\mathrm{CT}(\mathrm{w})=1.895,71+0,5954123 \times \mathrm{W}
$$

em que,

W - lâmina de irrigação (mm).

A análise de viabilidade econômica realizada neste estudo foi efetuada com base nos fluxos líquidos de caixa esperados. Estes foram construídos partindo-se de um investimento inicial no equipamento de irrigação de $\mathrm{R} \$ 5.114,97 \mathrm{ha}^{-1}$, por um horizonte temporal de 15 anos, a uma taxa de desconto igual a $6,75 \%$ ao ano. $\mathrm{O}$ valor residual foi considerado nulo, visto o horizonte temporal do projeto e a vida útil do equipamento de irrigação terem coincidido para esta análise.

Os resultados das tecnologias de manejo da irrigação sobre a produção do feijão-caupi, na análise da viabilidade econômica, estão apresentados na Tabela 2. Como se vê, independentemente da tecnologia adotada e das épocas de cultivo, os indicadores apontam para um investimento viável, considerando as condições edafoclimáticas da região dos cocais maranhenses. Resultado semelhante foi obtido por MOUSINHO (2005), indicando que a prática da irrigação garante a viabilidade econômica do cultivo do feijão-caupi, independentemente da época do ano. ANDRADE JÚNIOR (2000) também apontou para a viabilidade da produção irrigada do feijão-caupi, 
independentemente da época de semeadura, desde que a irrigação fosse bem manejada. RAMOS (2011) avaliou estratégias de irrigação do feijão-caupi, para a produção de grãos verdes em Teresina-PI, e também encontrou viabilidade econômica do manejo de irrigação para produção de grãos verdes ou vagens verdes do feijão-caupi.

TABELA 2. Indicadores de viabilidade econômica do feijão-caupi irrigado em função de diferentes tecnologias de manejo, em duas épocas de cultivo, em Codó-MA. Economic feasibility indicators of irrigated cowpea for different management technologies in two cropping seasons in Codó-MA, B razil.

\begin{tabular}{|c|c|c|c|c|c|c|c|}
\hline \multirow{2}{*}{ Tratamento } & \multirow{2}{*}{ Época } & \multirow{2}{*}{ Prod. $\left(\mathrm{kg} \mathrm{ha}^{-1}\right)$} & \multirow{2}{*}{$\begin{array}{c}\mathrm{CT}^{4} \\
\left(\mathrm{R} \$ \mathrm{ha}^{-1}\right) \\
\end{array}$} & \multirow{2}{*}{$\begin{array}{c}\text { Preço } \\
\left(\mathrm{R} \$ \mathrm{~kg}^{-1}\right)\end{array}$} & \multicolumn{3}{|c|}{ Indicadores de viabilidade } \\
\hline & & & & & $\mathrm{VPL}^{1}(\mathrm{R} \$)$ & $\mathrm{TIR}^{2}(\%)$ & $\mathrm{B} / \mathrm{C}^{3}$ \\
\hline \multirow[t]{2}{*}{$\mathrm{T} 1$} & $\mathrm{P}$ & $2.890,59$ & $2.034,47$ & 3,05 & $57.640,64$ & 132,59 & 3,41 \\
\hline & $\mathrm{O}$ & $2.070,73$ & $1.968,38$ & 2,10 & $16.909,78$ & 46,38 & 1,72 \\
\hline \multirow[t]{2}{*}{$\mathrm{T} 2$} & $\mathrm{P}$ & $2.438,35$ & $2.002,10$ & 3,05 & $45.176,38$ & 106,25 & 2,91 \\
\hline & $\mathrm{O}$ & $1.749,19$ & $1.980,86$ & 2,10 & $10.546,01$ & 32,61 & 1,45 \\
\hline \multirow[t]{2}{*}{$\mathrm{T} 3$} & $\mathrm{P}$ & $2.630,20$ & $2.004,29$ & 3,05 & $50.570,08$ & 117,65 & 3,14 \\
\hline & $\mathrm{O}$ & $2.221,70$ & $1.961,50$ & 2,10 & $19.907,12$ & 52,77 & 1,86 \\
\hline \multirow[t]{2}{*}{$\mathrm{T} 4$} & $\mathrm{P}$ & $3.075,17$ & $2.001,84$ & 3,05 & $63.151,94$ & 144,23 & 3,67 \\
\hline & $\mathrm{O}$ & $1.892,37$ & $1.963,35$ & 2,10 & $13.490,38$ & 39,03 & 1,58 \\
\hline \multirow[t]{2}{*}{ T5 } & $\mathrm{P}$ & $3.266,70$ & $2.013,43$ & 3,05 & $68.450,40$ & 155,43 & 3,88 \\
\hline & $\mathrm{O}$ & $1.674,20$ & $1.959,94$ & 2,10 & $9.282,36$ & 29,81 & 1,40 \\
\hline \multirow[t]{2}{*}{ T6 } & $\mathrm{P}$ & $2.017,62$ & $2.018,60$ & 3,05 & $33.149,61$ & 80,83 & 2,39 \\
\hline & $\mathrm{O}$ & $1.720,74$ & $1.979,73$ & 2,10 & $10.003,67$ & 31,41 & 1,43 \\
\hline \multirow[t]{2}{*}{$\mathrm{T} 7$} & $\mathrm{P}$ & $2.524,10$ & $1.989,38$ & 3,05 & $47.714,34$ & 111,61 & 3,03 \\
\hline & $\mathrm{O}$ & $1.818,65$ & $1.967,91$ & 2,10 & $12.015,65$ & 35,83 & 1,52 \\
\hline
\end{tabular}

1:VPL - valor presente líquido; 2:TIR - taxa intera de retorno; 3:B/C - relação benefício-custo; 4:CT - custo total de produção; T1 determinação da umidade do solo com uso do forno de micro-ondas; T2 - tanque Classe A; T3 - Irrigâmetro; T4 - tensiometria; T5 Irrígrafo; T6 - balanço hídrico com software Ref-ET; T7 - Balanço hídrico com software Irriplus; P - primavera; O - outono.

A obtenção dos preços do produto foi resultado de pesquisa realizada no município de Codó-MA, pertencente à região dos cocais, com aplicação de questionário semiestruturado junto aos produtores rurais, comerciantes intermediários e varejistas, no período de 2010 a 2012, durante as safras e entressafras dos respectivos anos. O propósito dos questionários terem sido aplicados em três elos da cadeia produtiva do feijão-caupi foi, unicamente, para confrontar as informações acerca do preço do produto, não tendo o objetivo de estudar a cadeia como um todo. Desta forma, considerou-se o preço médio pago ao produtor para o período em análise igual a $\mathrm{R} \$ 3,05 \mathrm{~kg}^{-1}$ na entressafra (primavera) e $\mathrm{R} \$ 2,10 \mathrm{~kg}^{-1}$ na safra (outono). Embora elevados, estes preços estão abaixo dos valores médios encontrados por ALVES et al. (2009), quando realizaram avaliação agroeconômica da produção consorciada do feijão-caupi e mandioca, em Boa Vista-RR, que obtiveram preços médios de $\mathrm{R} \$ 4,00 \mathrm{~kg}^{-1}$.

O valor presente líquido (VPL), a taxa interna de retorno (TIR) e a relação benefício custo (B/C) foram maiores com o manejo da irrigação realizado com o Irrígrafo (T5) e com o Irrigâmetro (T3) na primavera e outono, respectivamente. Os menores valores foram obtidos com os cultivos cuja irrigação foi manejada com o auxílio do software Ref-ET (T6), na primavera, e o Irrígrafo, no outono. As demais tecnologias tiveram valores intermediários.

De acordo com os dados apresentados na Tabela 2, verifica-se que o valor do VPL para o Irrígrafo, na primavera, foi $\mathrm{R} \$ 68.450,40 \mathrm{ha}^{-1}$, ao passo que, no outono, foi de $\mathrm{R} \$ 9.282,61 \mathrm{ha}^{-1}$. Com o Ref-ET, o VPL, na primavera, foi de R\$33.149,61 ha ${ }^{-1}$, e o Irrigâmetro, no outono, de R\$ $19.907,12 \mathrm{ha}^{-1}$. Assim, percebe-se que mesmo os menores valores de VPL sugerem bons retornos da atividade ao investidor. Ou seja, o produtor recuperaria seu capital, incrementando seu valor em um montante igual ao valor apresentado pelo VPL. A variação do VPL entre as tecnologias de manejo da irrigação, no cultivo da primavera, foi equivalente a $106,5 \%$, ao passo que, no outono, foi de $114,5 \%$. Quando se observa a redução entre cultivos, verifica-se uma variação média de $322,5 \%$ no 
segundo em relação ao primeiro plantio. Ou seja, uma grande diminuição da rentabilidade da cultura no cultivo efetuado no outono, pois além de ter proporcionado menores produtividades, os preços do produto foram menores.

A TIR calculada foi, em média, igual a $121,2 \%$ e $38,3 \%$ para os cultivos da primavera e outono, respectivamente, havendo a variação média entre as épocas de cultivo de $227,8 \%$. No cultivo realizado na primavera, a TIR variou de $155,43 \%$ a $80,83 \%$, sendo que no outono variou de $52,77 \%$ a $29,81 \%$. Estas taxas mostraram-se muito atrativas, principalmente num cenário econômico como o atual, de queda da taxa de juros. Comparando-se a TIR com a taxa de desconto de $6,75 \%$ ao ano, nota-se que todos os tratamentos se apresentam economicamente viáveis. $\mathrm{Na}$ primavera, o manejo da irrigação realizado com o irrígrafo permitiu a TIR de 155,43\%, apresentando maior retorno ao capital investido. Já o menor retorno foi conseguido com o balanço hídrico utilizando-se do software Ref-ET (80,83\%). No cultivo do outono, o irrígrafo possibilitou a TIR de 29,81\%, classificando-o como a tecnologia com menor TIR, dentre as tecnologias de manejo da irrigação estudadas. Para esta época, o maior valor da TIR foi obtido com o uso do irrigâmetro $(52,77 \%)$. Estes valores da TIR classificam o investimento na produção de feijão-caupi irrigado como bastante atrativo, independentemente da época de cultivo e da tecnologia de manejo da irrigação utilizada.

Corroborando mais uma vez os resultados, os valores do indicador relação benefício-custo (B/C) evidenciam que o manejo da irrigação realizado com o irrígrafo $(3,88)$, para a primavera, e o irrigâmetro $(1,86)$, para o outono, foram as tecnologias que proporcionaram a maior rentabilidade na produção de feijão-caupi. A média da $\mathrm{B} / \mathrm{C}$ foi 3,2 e 1,6 para a primavera e outono, respectivamente. Ou seja, para cada $\mathrm{R} \$ 1,00$ investido, a atividade permitiu um retorno líquido de $\mathrm{R} \$ 3,20$ ou $\mathrm{R} \$ 1,60$, em média.

É importante ressaltar que os resultados econômicos originados desta pesquisa foram gerados por meio de fluxos de caixa determinísticos, ou seja, considerando-se todas as variáveis (receitas e custos) constantes ao longo do tempo. Além disto, não foi realizada análise de sensibilidade do VPL; isto é, não se analisou mudança no VPL ao se alterar parâmetros relevantes, tais como taxa de juros, preço do produto, custos, etc. Além disto, esta análise não considerou a presença de riscos.

Valores de B/C superiores aos encontrados neste trabalho foram obtidos por ALVES et al. (2009), quando avaliaram economicamente a produtividade de feijão-caupi em consórcio com mandioca, em Roraima, e achou valores iguais a 5,75.

Portanto, nesta pesquisa, verificou-se que mesmo a menor rentabilidade obtida com o cultivo do feijão-caupi irrigado na primavera ainda é superior à obtida no outono, independentemente da tecnologia de manejo adotada. Pois, associado à maior produtividade de grãos secos, o preço do produto na época de entressafra (primavera) foi mais atrativo (o que é comum) para o período em análise. Ou seja, visto que se considerou apenas um cultivo do feijão-caupi por ano, na mesma área, observou-se que a época da semeadura na primavera foi mais rentável para as condições edafoclimáticas pesquisadas.

Embora a produção do feijão-caupi tenha-se mostrado economicamente atrativa com uso de qualquer uma das tecnologias de manejo da irrigação estudadas, as tecnologias, além do irrígrafo e irrigâmetro, que permitiram maiores rentabilidades, foram a tensiometria (primavera) e o balanço hídrico com determinação da umidade do solo com uso de forno de micro-ondas (para os cultivos da primavera e outono).

\section{CONCLUSÕES}

Em uma análise na qual não houve consideração dos riscos da atividade, o investimento na produção do feijão-caupi irrigado por aspersão convencional, nas condições edafoclimáticas da região dos cocais maranhenses, mostrou-se viável, independentemente da época de cultivo e/ou da tecnologia de manejo adotada. Entre as épocas de cultivo, observou-se que o plantio conduzido na 
época da primavera foi mais rentável para todos os tratamentos. A maior rentabilidade foi obtida com o manejo da irrigação realizado com o irrígrafo, na primavera, e com o irrigâmetro, no outono.

\section{AGRADECIMENTOS}

À Fund ação de Amparo à Pesquisa do Estado do Maranhão, à Universidade Federal de Viçosa e ao Instituto Federal de Educação, Ciência e Tecnologia do Maranhão, Campus Codó, pelo apoio à pesquisa.

\section{REFERÊNCIAS}

ALVES, J. M. A.; ARAÚJO, N. P. de; UCHÔA, S. C. P.; ALBUQUERQUE, J. de A. A. de; SILVA, A. J.; RODRIGUES, G. S.; SILVA, P. C. O. Avaliação agroeconômica da produção de cultivares de feijão-caupi em consórcio com cultivares de mandioca em Roraima. Revista Agro@mbiental On-line, Boa Vista, v.3, p. 15-30, 2009.

ANDRADE JÚNIOR, A.S. Viabilidade da irrigação, sob risco climático e econômico, nas microrregiões de Teresina e Litoral Piauiense. 2000, Tese (Doutorado) - Escola Superior de Agricultura Luiz de Queiroz, Universidade de São Paulo, Piracicaba, 2000.

ANDRADE JÚNIOR, A.S.; RODRIGUES, B.H.N.; FRIZZONE, J.A.; CARDOSO, M.J.; BASTOS, E.A.; MELO, F.B. Níveis de irrigação na cultura do feijão-caupi. Revista Brasileira de Engenharia Agrícola e Ambiental, Campina Grande, v.6, n.1, p.17-20, 2002.

ANEEL - Agência Nacional de Energia Elétrica. Resolução homologatória nº 1.194, de 23 de agosto de 2011. Brasília.

BERNARDO, S. Impacto ambiental da irrigação no Brasil. In: WORKSHOP INTERNACIONAL DE INOVAÇÕES TECNOLÓGICAS NA IRRIGAÇÃO (WINOTEC), 2.; SIMPÓSIO BRASILEIRO SOBRE O USO MÚLTIPLO DA ÁGUA, 1., 2008, Fortaleza. Palestras...

CARDOSO, M.J.; ANDRADE JUNIOR, A.S.; MELO, F.B.; FROTA, A.B. Avaliação Agroeconômica da produção de sementes de caupi sob irrigação. Teresina: EMBRAPA/CPAMN, Comunicado Técnico, 62. 1995, 6p.

BNB - Banco do Nordeste do Brasil. Fundo constitucional de financiamento do Nordeste: Programa Regional. Fortaleza: FNE 2012, 2011.

FIGUEIREDO, M. G.; FRIZZONE, J. A.; PITELLI, M. M.; REZENDE, R. Lâmina ótima de irrigação do feijoeiro, com restrição de água, em função do nível de aversão ao risco do produtor. Acta Scientia rum. Agronomy. Maringá, v. 30, n. 1, p. 81-87, 2008.

FRANKE, A. E. Avaliação econômica da irrigação, sob condições de risco, nas condições edafoclimáticas do Planalto Médio de Missões, RS. 1996. 116 f. Tese (Doutorado) - Instituto de Pesquisas Hidráulicas, Universidade Federal do Rio Grande do Sul, Porto Alegre, 1996.

FREIRE FILHO, F. R.; LIMA, J. A. de A.; RIBEIRO, V. Q. Feijão-caupi: avanços tecnológicos. Brasília, DF. Embrapa Informação Tecnológica, 2005, 519 p.

FRIZZONE, J. A. Otimização do uso da água na agricultura irrigada: perspectivas e desafios. Engenharia Rural, Piracicaba, v. 15, p. 37-56, 2004. Número Único.

FRIZZONE, J. A. Planejamento da irrigação com uso de técnicas de otimização. Revista Brasileira de Agricultura Irriga da, Fortaleza, v.1, n.1, p.24-49, 2007.

FRIZZONE, J.A.; ANDRADE JÚNIOR, A.S. de. Planejamento de irrigação: análise de decisão de investimento. Brasília, DF: Embrapa Informação Tecnológica, 2005. 626 p.

JOBIM, C. I.; MATTUELLA, J.; LOUZADA, J. A. Viabilidade econômica da irrigação do feijão no Planalto Médio do Rio Grande do Sul. Revista de Gestão de Água da América Latina, Bento Gonçalves, v. 6, n. 1, p. 5-15, jan./jun. 2009. 
MARQUES, P.A.A. Modelo computacional para determinação do risco econômico em culturas irrigadas. 2005. 142 f. Tese (Doutorado) - Escola Superior de Agricultura Luiz de Queiroz, Universidade de São Paulo, Piracicaba, 2005. Disponível em: <http://www.teses. usp.br/>. Acesso em: 5 fev. 2012.

MOUSINHO, F.E.P. Viabilidade econômica da irrigação do feijão-caupi no estado do Piaú. 2005. 103 f. Tese (Doutorado) - Escola Superior de Agricultura Luiz de Queiroz, Universidade de São Paulo, Piracicaba, 2005.

OLIVEIRA, S.de. Novo grão no cerrado. Revista Globo Rural, São Paulo, v. 26, n. 302, p. 46-49, dez. 2010.

RAMOS, H. M. M. Características produtivas, fisiológicas e econômicas do feijão-caupi para grãos verdes sob diferentes regimes hídricos. 2011. 109 f. Dissertação (Mestrado) - Universidade Federal do Piauí, Teresina, 2011.

SOUZA, J. L. M. Modelo pa ra análise de risco econômico aplicado ao plane jamento de projetos de irrigação para a cultura do cafeeiro. 2001. $253 \mathrm{f}$. Tese (Doutorado) - Escola Superior de Agricultura "Luiz de Queiroz", Universidade de São Paulo, Piracicaba, 2001.

TURCO, J. E. P.; RIZZATTI, G. dos S.; PAVANI, L. C. Custo de energia elétrica em cultura do feijoeiro irrigado por pivô central, afetado pelo manejo da irrigação e sistemas de cultivo. Revista Engenharia Agrícola, Jaboticabal, v.29, n.2, p.311- 320, abr.jun. 2009. 